\title{
Metagenomic analysis exploring taxonomic and functional diversity of soil microbial communities in Chilean vineyards and surrounding native forests
}

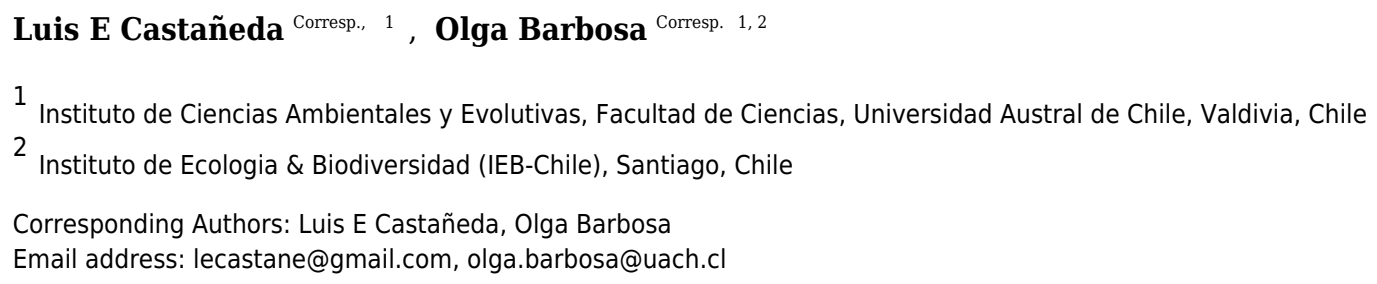

Mediterranean biomes are biodiversity hotspots, and vineyards are important components of the Mediterranean landscape. Over the last few decades, the amount of land occupied by vineyards has augmented rapidly, thereby increasing threats to Mediterranean ecosystems. Land use change and agricultural management have important effects on soil biodiversity, because they change the physical and chemical properties of soil. These changes may also have consequences on wine production considering that soil is a key component of terroir. Here we describe the taxonomic diversity and metabolic functions of bacterial and fungal communities present in forest and vineyard soils in Chile. To accomplish this goal, we collected soil samples from organic vineyards in central Chile and employed a shotgun metagenomic approach to sequence the microbial DNA. Additionally, we studied the surrounding native forest to obtain a baseline of the soil conditions in the area prior to the establishment of the vineyard. Our metagenomic analyses revealed that both habitats shared most of the soil microbial species. The most abundant genera in the two habitats were the bacteria Candidatus Solibacter and Bradyrhizobium and the fungus Gibberella. Our results suggest that the soil microbial communities are similar in these forests and vineyards. Therefore, we hypothesize that native forests surrounding the vineyards may be acting as a microbial reservoir buffering the effects of the land conversion. Regarding the metabolic diversity, we found that genes pertaining to the metabolism of amino acids, fatty acids, and nucleotides as well as genes involved in secondary metabolism were enriched in forest soils. On the other hand, genes related to miscellaneous functions were more abundant in vineyard soils. These results suggest that the metabolic function of microbes found in these habitats differs, though differences are not related to taxonomy. Finally, we propose that the implementation of environmentally friendly practices by the wine industry may help to maintain the microbial diversity and ecosystem functions associated with natural habitats. 


\section{Metagenomic analysis exploring taxonomic and metabolic diversity of soil}

\section{2 microbial communities in vineyards and surrounding native forests}

3

4 Luis E. Castañeda ${ }^{1}$ and Olga Barbosa ${ }^{1,2, *}$

5

6 Instituto de Ciencias Ambientales y Evolutivas, Facultad de Ciencias, Universidad Austral de

7 Chile, Valdivia, Chile.

8 2Instituto de Ecología \& Biodiversidad (IEB-Chile), Casilla 653, Santiago, Chile.

9

10

$11 *$ Corresponding author: Olga Barbosa

12 Instituto de Ciencias Ambientales y Evolutivas

13 Facultad de Ciencias, Valdivia 5090000, Chile

14 E-mail: olga.barbosa@uach.cl

15

16 Running title: Metagenomics in forest and vineyard soils 


\section{Abstract}

19 Mediterranean biomes are biodiversity hotspots, and vineyards are important components of the

20 Mediterranean landscape. Over the last few decades, the amount of land occupied by vineyards

21 has augmented rapidly, thereby increasing threats to Mediterranean ecosystems. Land use change

22 and agricultural management have important effects on soil biodiversity, because they change

23 the physical and chemical properties of soil. These changes may also have consequences on wine

24 production considering that soil is a key component of terroir. Here we describe the taxonomic

25 diversity and metabolic functions of bacterial and fungal communities present in forest and

26 vineyard soils in Chile. To accomplish this goal, we collected soil samples from organic

27 vineyards in central Chile and employed a shotgun metagenomic approach to sequence the

28 microbial DNA. Additionally, we studied the surrounding native forest to obtain a baseline of the

29 soil conditions in the area prior to the establishment of the vineyard. Our metagenomic analyses

30 revealed that both habitats shared most of the soil microbial species. The most abundant genera

31 in the two habitats were the bacteria Candidatus Solibacter and Bradyrhizobium and the fungus

32 Gibberella. Our results suggest that the soil microbial communities are similar in these forests

33 and vineyards. Therefore, we hypothesize that native forests surrounding the vineyards may be

34 acting as a microbial reservoir buffering the effects of the land conversion. Regarding the

35 metabolic diversity, we found that genes pertaining to the metabolism of amino acids, fatty acids,

36 and nucleotides as well as genes involved in secondary metabolism were enriched in forest soils.

37 On the other hand, genes related to miscellaneous functions were more abundant in vineyard

38 soils. These results suggest that the metabolic function of microbes found in these habitats differs,

39 though differences are not related to taxonomy. Finally, we propose that the implementation of 
40 environmentally friendly practices by the wine industry may help to maintain the microbial

41 diversity and ecosystem functions associated with natural habitats.

42

\section{Introduction}

44 Being one of the main drivers of global change, land use change affects many important 45 ecosystem properties and functions (Vitousek et al., 1997). Land use change (also referred to 46 here as land conversion) has consequences at ecosystem scales because ecological functions can

47 be lost during the conversion of native habitats (Griffiths \& Philippot, 2013). Particularly in 48 Mediterranean biomes, land conversion has occurred at very rapid rates over the last decades 49 (Cincotta, Wisnewski \& Engelman, 2000; Lauber et al., 2008; Underwood et al., 2008). This is 50 especially important given that Mediterranean ecosystems are classified as biodiversity hotspots 51 due to the high diversity of plant species and high endemism in these areas (Cowling et al., 1996; 52 Myers et al., 2000). Therefore, conservation programs are necessary to preserve the biodiversity 53 of these ecosystems.

54 The Mediterranean climate is suitable for viticulture; subsequently vineyards are 55 becoming important components of Mediterranean landscapes due to the development of the 56 wine industry in these regions (Hannah et al., 2013; Viers et al., 2013). Land occupied by 57 vineyards increased by 70\% between 1988 and 2010 in New World Mediterranean zones (Chile, 58 the Californias, Australia, and South Africa) (Viers et al., 2013). By replacing natural landscapes 59 and by simplifying the structure and composition of ecological communities (Viers et al. 2013),

60 the expansion of vineyards threatens Mediterranean ecosystems. In addition, agricultural 61 management (e.g. tillage, pesticide, and fertilizer applications) directly affects soil biodiversity

62 by altering the physical and chemical properties of soil (Pampulha \& Oliveira, 2006; Jangid et al., 
63 2008). For instance, organically managed vineyards have higher soil microbial biomass and

64 nematode densities than conventional vineyards (Coll et al., 2012). On the other hand, Bevivino

65 et al. (2014) report that undisturbed soils have more stable bacterial communities throughout the

66 change of seasons than do vineyards. This suggests that natural habitats are more resilient to

67 environmental or human perturbations. Furthermore, soil biodiversity is very significant to wine

68 production, which relies on soil and climatic conditions as key components of terroir (van

69 Leeuwen et al., 2004; Gilbert, van der Lelie \& Zarraonaindia, 2014).

The soil horizon is one of the most diverse environments on Earth; currently it is

71 estimated that thousands of different microbial species inhabit one gram of soil (Delmont et al.,

72 2011; Xu et al., 2014). There is abundant evidence confirming the important role played by soil

73 microorganisms in several ecosystem services such as erosion control, soil formation, nutrient

74 cycling, and plant health (Tiedje et al., 1999; Nanniepieri et al., 2003; Garbeva, van Veen \& van

75 Elsas, 2004; Gardi et al., 2009). However, soil microbial communities are not static and can

76 change across agricultural practices and environmental gradients (Bevivino et al., 2014; García-

77 Orenes et al., 2013). For instance, the addition of organic matter to managed soils increases

78 fungal abundance and causes the microbial community structure to resemble that of undisturbed

79 forest soil (García-Orenes et al., 2013). In addition, Corneo et al. (2013) report that microbial

80 communities change across altitudinal gradients, where soil physical (e.g. soil moisture, clay

81 content) and chemical (e.g. aluminum, magnesium, molybdenum, boron) properties explain most

82 of the altitudinal variation in soil communities.

83 The recent development of high-throughput sequencing techniques has allowed a deeper

84 understanding of the microbial diversity of vineyard soils in different wine-producing regions

85 around the world (Corneo et al., 2013; Fujita et al., 2010; Zarraonaindia et al., 2015). Although 
86 Mediterranean Chile is one of the most important wine-producing regions and the area occupied

87 by vineyards in Chile has rapidly expanded (Viers et al., 2013), there are very few studies

88 exploring the microbial diversity of these vineyard soils (but see Aballay et al., 2011; Castañeda

89 et al., 2015). Recently, Castañeda et al. (2015) have shown that the soil bacterial communities in

90 native forests and vineyards are similar, whereas the fungal communities differ between the

91 habitats. This study employed T-RFLPs, which are reliable technique but do not provide deep

92 taxonomic resolution or information about the metabolic functioning of the microbial community.

93 In the present study, our goal is to describe the taxonomic diversity as well as the metabolic

94 functions of bacterial and fungal communities present in forest and vineyard soils in Chile. To

95 accomplish this goal, we assessed the taxonomic and metabolic diversity of soil samples from

96 three organic vineyards in central Chile; we employed a shotgun sequencing approach, paying

97 particular attention to species associated with viticulture and wine making. The organic

98 vineyards sampled are relatively young $(<10$ years old) and are surrounded by natural

99 landscapes. The surrounding natural landscapes are dominated by native sclerophyllous forests

100 and shrubs, thus these ecosystems likely represent the soil characteristics of the area before the

101 establishment of the vineyard. The knowledge of the soil microbial communities of native

102 habitats could provide valuable information for the conservation management of vulnerable

103 ecosystems (Heilmann-Clausen et al., 2014) such as for the Chilean Mediterranean region

104 (Mittermeier et al., 2011; Hannah et al., 2013; Viers et al., 2013). Knowledge of microbial

105 community dynamics found in this biome is scarce and metagenomic studies could provide a

106 starting point for the conservation of microbial diversity and for the preservation of ecosystem

107 functions provided by natural habitats (Gardi et al. 2009). 


\section{Materials and Methods}

110

\section{Sampling}

112 Soil samples were collected from three different organic vineyards and from neighboring

113 sclerophyllous forest patches in Central Chile; Ocoa (32 $\left.52^{\prime} \mathrm{S}-71^{\circ} 7^{\prime} \mathrm{W}\right)$, Leyda (33⒊' S -

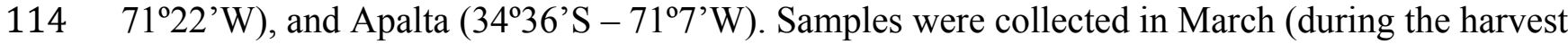

115 season) of 2012. The owners of the vineyards and the surrounding native forest patches granted

116 all necessary permits to access the sampling sites: Seña Vineyards in Ocoa (Chile), Cono Sur

117 Vineyards in Leyda (Chile), and Emiliana Vineyards in Apalta (Chile; Table 1). The vineyards

118 contain woody-perennial monocultures of Vitis vinifera, whereas the forest patches mainly

119 contain Cryptocarya alba, Peumus boldus, Quillaja saponaria, Lithrea caustica, and Acacia

120 caven, among other tree and shrub species.

121 In each vineyard, a plot near the forest patch was randomly selected. In each vineyard

122 plot, five vines each separated from the other by $3.5 \mathrm{~m}$ were randomly selected. One bulk soil

123 sample was collected at a distance of $5 \mathrm{~cm}$ from each vine stem; the soil samples were taken

124 from the first $15 \mathrm{~cm}$ of the soil horizon using soil cores. This depth was chosen because the

125 majority of microbial activity is thought to occur within the upper $15 \mathrm{~cm}$ (O'Brien et al., 2005).

126 The same procedure was performed in the adjacent forest patch, where five native trees and

127 corresponding soil samples were randomly selected and collected as previously described. All

128 collected samples were stored in a sterile bag and placed in a cooler with ice packs. During the

129 same day, the 30 soil samples were transported to the laboratory where they were individually

130 homogenized, sieved, and stored at $-80^{\circ} \mathrm{C}$ until DNA extraction was performed. 


\section{Metagenomic sequencing}

133 For a total of 30 soil samples ( 3 vineyards $\times 2$ habitats $\times 5$ soil samples), DNA was extracted

134 using the Power Soil DNA isolation kit (MoBio Laboratories Inc., Carlsbad, CA) following the

135 manufacturer's instructions. The quality of the DNA extracted was determined by

136 electrophoresis using a $0.8 \%$ agarose gel. Furthermore, the DNA was quantified using a

137 nanospectrophotometer (NanoDrop Technologies Inc., Wilmington, DE).

138 For sequencing, the DNA extractions from each habitat ( 5 samples) were pooled into one

139 sample. Thus, one pooled vineyard sample and one pooled forest sample were sequenced for

140 each vineyard (6 samples in total). The concentration of DNA was assessed by fluorescence

141 using the Quant-iT PicoGreen dsDNA kit (Invitrogen, Carlsbad, CA); fluorescence was

142 measured on a DQ 300 fluorometer (Hoefer Scientific Instruments, San Francisco, CA).

143 Following this, each metagenomic library was prepared using the 454 GS Junior Titanium Rapid

144 DNA library preparation kit according to the manufacturer's instructions. Emulsion PCR

145 (emPCR) was performed according to the Amplification Method Manual using a Lib-L kit. All

146 steps involved in massive DNA sequencing were performed in the AUSTRAL-omics Core-

147 Facility (Facultad de Ciencias, Universidad Austral de Chile) in a 454 GS Junior Titanium Series

148 (Roche, Branford, CT) following the standard protocol from Roche.

\section{Data analysis}

151 The raw sequences of each of the six metagenomes were uploaded to the MG-RAST server at

152 http://metagenomics.anl.gov (Meyer et al. 2008). The number of uploaded sequences ranged

153 from 141,694 to 195,138 sequences for the forest soil samples and from 189,372 to 208,095 for

154 the vineyard soil samples. After quality control was performed using MG-RAST, the number of 
155 retained sequences for the forest soil samples ranged from 114,120 to 131,618 with an average

156 length of $442.7 \mathrm{bp}$, whereas 108,385 to 138,101 sequences with an average length of $445.3 \mathrm{bp}$

157 were retained for the vineyard soil samples (see Table S1 for more detailed information).

158 Taxonomic assignments were performed using the SEED database, and metabolic assignments

159 were performed using the Subsystems database. For both types of assignments, we employed a

160 maximum e-value of $1 \mathrm{e}-5$, a minimum identity of $60 \%$, and a maximum alignment length of 15

161 bp. The accession numbers for the metagenomes in the MG-RAST server

162 (http://metagenomics.anl.gov/metagenomics.cgi?page=MetagenomeProject\&project=8742) are:

$1634565458.3,4565459.3,4565460.3,4565461.3,4565462.3$, and 4565463.3. Rarefaction curves

164 for each of the samples reached appropriate taxonomic depth as can be seen in Fig. S1.

165 For taxonomic analysis, the OTU table was downloaded from the MG-RAST server and

166 analyzed in QIIME v1.9.1 (Caporaso et al., 2010). OTUs that matched the follow criteria were

167 removed from the OTU table: (1) OTUs matched to mitochondria, chloroplast, plant or animal

168 sequences; (2) OTUs observed fewer than 10 times; and (3) OTUs observed in fewer than two

169 samples. The resulting OTU table was analyzed employing the vegan (Oksanen et al., 2013) and

170 phyloseq (McMurdie \& Holmes, 2013) packages in R (R Development Core Team, 2011). To

171 standardize the number of sequences between samples, they were rarefied to 289,800 sequences.

172 Venn diagrams were made to visualize which OTUs were shared between forest and vineyard

173 soils using Venny 2.1.0 (Oliveros, 2015). Species richness, Shannon diversity, and Pielou

174 evenness indices were estimated for each of the samples, and these indices were compared

175 between habitats using a Kruskal-Wallis test. Beta diversity was estimated using Bray-Curtis

176 dissimilarity, employing the vegdist function of the vegan package in R. Then, a permutational

177 multivariate analysis of variance (PERMANOVA) was used to compare the microbial 
178 community structure between forest and vineyard soils; this was performed with 999

179 permutations using the adonis function of the vegan package in R. Finally, a canonical

180 correspondence analysis (CCA) conducted in vegan was used to visualize the community

181 structure.

182 To analyze the metabolic profiles, the relative abundances of reads in forest and vineyard

183 soils were compared via a White's non-parametric t-test (White, Nagarajan \& Pop, 2009) using

184 the software STAMP (Parks \& Beiko, 2010). Comparisons of metabolic profiles between

185 habitats were performed using a PERMANOVA analysis; this was done using the adonis

186 function of vegan in R. Finally, canonical correspondence analysis (CCA) conducted in vegan

187 was used to visualize the functional-based community structure and the relationship between soil

188 samples and functional categories.

189 Finally, raw datasets and specific analyses are available at the Figshare server

190 (https://dx.doi.org/10.6084/m9.figshare.2058060.v2).

191

192

193 Results

194 Taxonomical analysis

195 Metagenomic analyses using the SEED database showed that Bacteria, followed by Eukaryota

196 and Archaea, dominated the forest as well as the vineyard soil samples. The other sequences

197 corresponded to Viruses and unassigned sequences (Table 2). Among Bacteria, Proteobacteria

198 was the most abundant phylum both in forest soil as well as in vineyard soil; which was followed

199 by Actinobacteria, Acidobacteria, Bacteriodetes, Firmicutes, and Planctomycetes (Table 2).

200 However, we did not find significant differences in the relative abundances of these phyla (Table 
201 2). By taking a closer look at the taxonomy, we found 4104 bacterial OTUs (97\% nucleotide ID)

202 corresponding to 1326 species, of which $87.1 \%$ were shared between habitats (Fig. 1). The ten

203 most abundant species were Candidatus Solibacter usisatus (pooled mean $=2.5 \%, \mathrm{P}=0.83$ ),

204 Bradyrhizobium japonicum (pooled mean $=2.5 \%, \mathrm{P}=0.51$ ), Rhodopseudomonas palustris

205 (pooled mean $=2.1 \%, \mathrm{P}=0.51)$, Conexibacter woesei $($ pooled mean $=1.9 \%, \mathrm{P}=0.83)$,

206 Candidatus Koribacter versatilis (pooled mean $=1.7 \%, \mathrm{P}=0.83$ ), Gemmatimonas aurantiaca

207 (pooled mean $=1.5 \%, \mathrm{P}=0.28)$, Sorangium cellulosum $($ pooled mean $=1.4 \%, \mathrm{P}=0.83)$,

208 Mycobacterium tuberculosis (pooled mean $=1.4 \%, \mathrm{P}=0.51)$, Rhodopirellula baltica $($ pooled

209 mean $=0.9 \%, \mathrm{P}=0.83)$, and Myxococcus xanthus $($ pooled mean $=0.9 \%, \mathrm{P}=0.51)$. Nevertheless,

210 there were no significant differences in the relative abundances of these dominant species in

211 forest and vineyard soils. Conversely, the relative abundances of 36 OTUs were significantly

212 different between habitats $(P<0.05)$; but all of these OTUs were found in very low relative

213 abundances in both habitats. We also explored the presence of lactic acid (Lactobacillaceae and

214 Leuconostocaceae) and acetic bacteria (Acetobacteraceae) in the forest and vineyard soils; lactic

215 acid is known to positively affect wine production while acetic bacteria negatively affects

216 production. Typically, these bacteria are found in low relative abundances in soil samples, but

217 we expected they might be found in the sampled vineyards, being derived from the grape skins

218 that are often used as fertilizer. We found the presence of lactic acid bacteria including

219 Lactobacillus (vineyard $=0.04 \%$ and forest $=0.03 \%, \mathrm{P}=0.51$ ) and acetic bacteria such as

220 Gluconobacter $($ vineyard $=0.038 \%$ and forest $=0.041 \%, \mathrm{P}=0.51)$ and Acetobacter $($ vineyard $=$

$2210.13 \%$ and forest $=0.12 \%, \mathrm{P}=0.82$ ).

222 For the Eukaryota domain, we focused on fungal OTUs, which were mainly related to the

223 phyla Ascomycota and Basidiomycota (Table 2). We found 95 fungal OTUs (97\% nuclotide ID) 
224 corresponding to 47 Ascomycota and 8 Basidiomycota species. Among the most abundant

225 fungal-related OTUs, we found the Ascomycota Gibberella zeae (vineyard $=0.040 \%$ and forest

$226=0.0042 \%, \mathrm{P}=0.83)$, Aspergillus fumigatus $($ vineyard $=0.03 \%$ and forest $=0.05 \%, \mathrm{P}=0.13)$,

227 and Neurospora crassa (vineyard $=0.026 \%$ and forest $=0.029 \%, \mathrm{P}=0.28$ ). Exploring the

228 presence of fermenting yeasts in soil, we found some OTUs related to Saccharomyces cerevisiae

229 (97\% identity), which were significantly more abundant in forest $(0.002 \%)$ than in vineyard

$230(0.004 \%)$ soils $(\mathrm{P}=0.046)$. Another important group found in both habitats was the domain

231 Archaea represented by its five phyla: Crenarchaeota, Euryarchaeota, Korarchaeota, and

232 Thaumarchaeota. Of these, the phylum Euryarchaeota was the most abundant, but no significant

233 differences were found between the Archaea of forest and vineyard soils (Table 2).

234 Microbial community analyses showed that vineyards had higher species richness than

235 forests, while the Shannon diversity, Shannon richness, and evenness indices were not

236 significantly different between the habitats (Table 3A). We also found that the microbial

237 community structure did not differ between habitats (PERMANOVA, $\mathrm{P}=0.45$ ); this is

238 illustrated in the CCA plot (Fig. 2).

239

\section{Functional analysis}

241 Functional metabolic categories related to microorganisms found in forest and vineyard soils are 242 represented in Figure 3. The most abundant functional categories included sequences related to 243 carbohydrate metabolism (forest mean $=14.4 \%$ and vineyard mean $=14.6 \%$ ), functionally 244 coupled genes but with unknown function (i.e. clustering-based on subsystems) (forest mean = $24514.0 \%$ and vineyard mean $=14.2 \%$ ), and metabolism of amino acids and their derivatives (forest 246 mean $=10.8 \%$ and vineyard mean $=10.6 \%$ ). We did not find differences between habitats in the 
247 microbial communities' functional profiles at the SEED level-1 gene annotation (PERMANOVA,

$248 \mathrm{P}=0.80$, Fig. 3), and any functional categories showed a clear association to any habitat type

249 (Fig. 3). Conversely, we found that genes related to metabolism of amino acids and their

250 derivatives $(P=0.007)$, fatty acid and lipid metabolism $(P=0.024)$, nucleoside and nucleotide

251 metabolism $(P=0.045)$, and secondary metabolism $(P=0.011)$ showed significantly higher

252 relative abundances in forest than vineyard soils (Fig. 4). On the other hand, only genes related

253 to miscellaneous functions $(P=0.033)$ showed a significantly higher relative abundance in

254 vineyard than forest soils (Fig. 4). Therefore, we explored the functional profiles of the

255 categories that showed significant abundance between habitats, but we did not find significant

256 differences in the microbial communities' metabolic profiles: amino acid metabolism

257 (PERMANOVA, $\mathrm{P}=0.22$ ), fatty acid metabolism (PERMANOVA, $\mathrm{P}=0.23$ ), nucleoside and

258 nucleotide metabolism (PERMANOVA, $\mathrm{P}=0.25$ ), secondary metabolism (PERMANOVA, $\mathrm{P}=$

259 0.40), and miscellaneous functions (PERMANOVA, $\mathrm{P}=0.23$ ).

260 Additionally, we explored some functional categories that could be associated with

261 nutrient cycling. From this, we found sequences related to sulfur metabolism (forest mean $=$

$2621.18 \%$ and vineyard mean $=1.15 \%$ ), phosphorous metabolism (forest mean $=1.04 \%$ and

263 vineyard mean $=1.05 \%)$, nitrogen metabolism $($ forest mean $=0.82 \%$ and vineyard mean $=$

$2640.80 \%$ ), and potassium metabolism (forest mean $=0.30 \%$ and vineyard mean $=0.33 \%$ ). The

265 relative abundances of these functions were similar in forest and vineyard soils $(P>0.1)$. We

266 also explored the SEED level-3 hierarchical gene annotation. In general, assimilation of

267 inorganic sulfur (overall mean $=0.37 \%)$, phosphate metabolism (overall mean $=0.54 \%$ ),

268 phosphorous uptake (overall mean $=0.20 \%$ ), ammonia assimilation (overall mean $=0.38 \%$ ),

269 nitrate and nitrite assimilation (overall mean $=0.15 \%$ ), and potassium homeostasis (overall mean 
$270=0.28 \%$ ) were the most abundant level-3 functions related to nutrient cycling. However, the

271 relative abundances of these functions were not significantly different between forest and

272 vineyard soils. We also estimated the species richness of OTUs related with some specific

273 functional categories (level 1 of SEED Subsystems hierarchy) such as nitrogen metabolism,

274 phosphorous metabolism, potassium metabolism, and defense-related genes. However, we did

275 not find any significant differences in alpha-diversity between habitats (Table 3B).

276

\section{Discussion}

278 Our analysis showed that bacterial-related OTUs had the highest relative abundance in both

279 habitats. For soil environments, Uroz et al. (2013) have reported similar bacterial abundances in

280 organic and mineral soils: bacterial sequences accounted for ca. $94 \%$ of the total sequences.

281 Proteobacteria are very common in soil environments and are related to a wide variety of

282 functions involved in carbon, nitrogen, and sulfur cycling (Spain, Krumholz \& Elshahed, 2009).

283 The relative abundances of Proteobacteria found in the present study are similar to those

284 previously reported for other soil types such as crops, forests, and grasslands (ca. 40\% according

285 to Janssen [2006]). Participating in carbon cycling and producing secondary metabolites,

286 Actinobacteria are also dominant in soils (Jenkins et al., 2010). In our study, the most abundant

287 bacterial genera in the soil samples were Candidatus Solibacter, Bradyrhizobium, Conexibacter

288 and Rhodopseudomonas, which have been previously reported as dominant genera in several

289 types of soil (Delmont et al., 2011; Pearce et al., 2012). Comparing bacterial phyla and genera,

290 we did not find differences in relative abundances between forest and vineyard soils.

291 Additionally, we found that diversity indices and microbial community structure were similar

292 between forest and vineyard soils; this agrees with our previous work performed using T-RFLPs 
293 (Castañeda et al., 2015). Conversely, these findings differ from previous evidence suggesting

294 that bacterial communities differ between forest and managed soils (García-Orenes et al., 2013).

295 However, the relationship between microbial diversity and habitat disturbance is very complex

296 and can depend on the degree of disturbance; some disturbed habitats can even exhibit higher

297 diversity than forest systems (Miura et al. 2016; Montecchia et al., 2015).

298 Similar to the bacterial community results, fungal communities did not differ between

299 habitats. Most of the fungi-related sequences were assigned to Ascomycota, outweighing other

300 groups such as Basidiomycota, which only represented a small fraction of the total fungal

301 sequences. At the species level, the most abundant fungal species was Gibberella zeae/Fusarium

302 graminearum, a well-known plant pathogen that attacks cereals (Bai \& Shaner, 2004). From a

303 comparative point-of-view, we found similar fungal abundance between forest and vineyard soils.

304 Interestingly, our previous work employing T-RFLPs showed that fungal community structure

305 differed between forest and vineyard soils (Castañeda et al., 2015); this agrees with another T-

306 RFLP-based study that shows that fungal diversity differs between native eucalyptus forests and

307 Pinus plantations in Australia (Kasel, Bennett \& Tibbits, 2008). It should be noted that the lack

308 of differences in fungal abundances in the present study might be related to the low

309 representation of fungal sequences in the soil samples. Additionally, differences in taxonomic

310 abundance could be limited to differences in functional taxonomic groups because taxonomic

311 assignment was based on the SEED non-redundant protein database (for additional information

312 see Carrino-Kyker, Smemo \& Burke, 2013). Therefore, complementary approaches such as

313 metatranscriptomic or amplicon-sequencing approaches should be employed to study soil

314 eukaryotic communities to gain a deeper understanding of the ecology of these communities. 
Microbes play important roles in several stages of wine production (Mills et al. 2008).

316 For instance, fermenting yeasts are involved in alcoholic fermentation (i.e. the conversion of

317 sugar into ethanol and carbon dioxide), and lactic acid bacteria perform malolactic fermentation

318 (i.e. the conversion of malate into lactate) (Fleet, 2003; Mills et al., 2008). Our data show the

319 presence of lactic acid bacteria such as Lactobacillus and Gluconobacter, acetic bacteria such as

320 Acetobacter, and the fermenting-yeast $S$. cerevisiae in the soil samples collected. Although these

321 species are not usually common in soils, we decided to search for them because organic

322 vineyards often use recycled grape skins (also know as pomace) as organic fertilizer. Knowing

323 this, one would expect that some lactic acid bacteria and fermenting yeasts could colonize, or at

324 least survive, in vineyard soils. Recently, Zarraonaindia et al. (2015) have reported that soil acts

325 as a source of grape-associated bacteria, and thus with edaphic factors, soil can influence

326 grapevine microbiota. However, the abundance of lactic acid, acetic, and fermenting microbes

327 was relatively low compared to other dominant taxa. This suggests, contrary to what has been

328 previously suggested (Bester, 2005; Chen, Yanagida \& Shinohara, 2005; Zarraonaindia et al.,

329 2015), that soil may not be a suitable ecological niche or reservoir for microorganisms important

330 to wine production. It must be noted, however, that differences in methodological approaches

331 may explain disparities between our findings and those previously reported: some studies have

332 employed enrichment methods (Bester, 2005; Chen, Yanagida \& Shinohara, 2005) or amplicon

333 sequencing (Zarraonaindia et al., 2015), while shotgun sequencing (technique employed in the

334 present study) could underestimate the abundance of fungal sequences. Future studies should

335 evaluate the presence of enologically important microorganisms in surrounding native flora (i.e.

336 leaves and fruits) to determine if these habitats are potential sources and/or reservoirs of

337 microbial diversity relevant to wine production. This is particularly interesting due to the fact 
338 that high-quality wines are strongly associated with the concept of terroir, which encompasses

339 regional characteristics such as climate and grape variety, and also gives special importance to 340 soil and the interactions that occur with microorganisms (Anonymous, 2010). The fact that

341 natural habitats can be potential reservoirs of microorganisms could safeguard the identity of 342 terroir over time.

343 Most sequences obtained from forest and vineyard soils were related to the metabolism of 344 carbohydrates and amino acids. This finding suggests that soil microbial communities are 345 capable of degrading carbohydrates and playing an important role in the carbon cycle through 346 organic matter and litter decomposition. Indeed, these results agree with the high relative 347 abundance $(\mathrm{ca} .12 \%)$ of genes related to carbohydrate metabolism previously reported for 348 organic soils (Uroz et al., 2013; Paula et al., 2014). On the other hand, land-use changes alter the 349 community structure of soil microorganisms and can have profound effects on ecosystem 350 functions and processes (Griffiths \& Philippot, 2013; Paula et al., 2014). In this sense, it has been 351 reported that the land conversion of primary forests to long-term pastures has changed the 352 microbial functional diversity of Amazon soils and especially so for genes related to carbon and 353 nitrogen cycling (Paula et al., 2014). In the present study, we found differences in the abundance 354 of genes related to the metabolism of amino acids and their derivatives, fatty acid and lipid 355 metabolism, nucleoside and nucleotide metabolism, secondary metabolism, and miscellaneous 356 functions. However, from a community perspective we did not detect differences in the 357 metabolic profiles nor did we find a difference in the number of microbial species related with 358 each metabolic function. We also explored functional categories of genes related to nutrient 359 metabolism and potentially involved in nutrient cycling (see Fierer et al., 2012). For instance, 360 nitrogen-related genes represented $0.8 \%$ of the total functional reads, and the abundances of 
361 these genes did not differ between forest and vineyard soils. These abundance values are in

362 concordance with previous studies, including environments enriched with nitrogen-fixing

363 bacteria such as in soybean crops (Mendes et al., 2014). A plausible explanation for the lack of

364 differences between habitats is that organic agriculture supplies nitrogen in its organic form (e.g.

365 compost and manure) similarly to what occurs in forests; thus nitrogen could be available in the

366 same chemical form in both habitats only in higher quantities in vineyards $\left(\mathrm{NH}_{4}\right.$ vineyard $=9.2$

$367 \mathrm{mg} / \mathrm{kg}$ and $\mathrm{NH}_{4}$ forest $=4.2 \mathrm{mg} / \mathrm{kg} ; \mathrm{NO}_{3}$ vineyard $=11.1 \mathrm{mg} / \mathrm{kg}$ and $\mathrm{NO}_{3}$ forest $=7.2 \mathrm{mg} / \mathrm{kg}$ ).

368

369 Conclusions

370 We explored the taxonomic and functional diversity of microbial communities in Chilean

371 vineyards using shotgun sequencing. We also analyzed the taxonomic and functional diversity of

372 microbial communities in forest soils of the Chilean Mediterranean biome, one of the most

373 threatened biodiversity hotspots in the world (Myers et al., 2000; Viers et al., 2013). Our

374 metagenomic analyses revealed that the soil microbial communities of organic vineyards and

375 native forests are similar, suggesting that taxonomic composition does not significantly differ

376 between habitats. Conversely, some functional categories differed between forest and vineyard

377 soils. These results could suggest that native forests surrounding vineyards act as microbial

378 reservoirs buffering land conversion. However, additional research is needed to explore the role

379 of landscape complexity and agriculture management on microbial communities in forest-

380 vineyard agroecosystems. Finally, we propose that the implementation of environmentally

381 friendly practices by the wine industry may help to maintain the microbial diversity and

382 ecosystem functions related to natural habitats. This will not only preserve biodiversity but also

383 help to maintain the typicity of wine, which is a valuable cultural and commercial characteristic. 


\section{Acknowledgments}

386 We thank Marlene Manzano for collecting soil samples, Andrea Silva for advice during the 387 metagenome sequencing, Juan Opazo for exploratory analysis on the sequencing data, and Juan 388 Ugalde and Toshiko Miura for their advice on the metagenomic analysis. We also thank 389 Elizabeth Cook and Emily Giles for their valuable suggestions and English editing of the 390 manuscript draft. Finally, we thank Keith Crandall and the anonymous reviewers for their 391 comments and suggestions that improved the quality of our manuscript.

392

393

\section{References}

394 395

396

397

398

399

400

401

402

403

404

405

406

Aballay E, Maternsson A, Persson P. Screening of rhizosphere bacteria from grapevine for their suppressive effect on Xiphinema index Thorne \& Allen on in vitro grape plants. Plant Soil. 2011;347: 313-325.

Anonymous. Definition of viticultural ‘Terroir'. Resolution OIV/VITI 333/2010. Tbilisi, Georgia. International Organization of Vine and Wine General Assembly (OIV). Available at http://www.oiv.int/public/medias/379/viti-2010-1-en.pdf (accessed 6 June 2016).

Bai G, Shaner G. Management and resistance in wheat and barley to Fusarium head blight. Annu Rev Phypathol. 2004;42: 135-161.

Bester R. Growth and survival of Saccharomyces cerevisiae in soil. MSc Thesis, University of Stellenbosch, South Africa. 2005. Available at http://scholar.sun.ac.za/handle/10019.1/16597 (Accessed 6 June 2016).

Bevivino A, Paganini P, Bacci G, Florio A, Pellicer MS, Papaleo MC, Mengoni A, Ledda L, Fani R, Benedetti A, Dalmastri C. Soil bacterial community response to differences in 
407

408

409

410

411

412

413

414

415

416

417

418

419

420

421

422

423

424

425

426

427

428

agricultural management along with seasonal changes in a Mediterranean region. PLoS One 2014;9: e105515.

Carrino-Kyker SR, Smemo KA, Burke DJ. Shotgun metagenomic analysis of metabolic diversity and microbial community structure in experimental vernal pools subjected to nitrate pulse. BMC Micriobiol. 2013;13: 78.

Castañeda LE, Manzano M, Godoy K, Marquet PA, Barbosa O. Comparative study between soil microbial structure communities from vineyards and sclerophyllous forest in Central Chile. Ecol Evol. 2015,5: 3857-3868.

Chen YS, Yanagida F, Shinohara T. Isolation and identification of lactic acid bacteria from soil using enrichment procedure. Lett Appl Micriobiol. 2005;40: 195-200.

Cincotta RP, Wisnewski J, Engelman R. Human population in biodiversity hotspots. Nature. 2000;404: 990-992.

Coll P, Le Cadre E, Blanchart E, Hinsinger P, Villenave C. Organic viticulture and soil quality: a long-term study in Southern France. Appl Soil Ecol. 2011;50: 37-44.

Corneo PE, Pellegrini A, Cappellin L, Roncador M, Chierici M, Gessler C, Pertot I. Microbial community structure in vineyard soils across altitudinal gradients and in different seasons. FEMS Microbiol Ecol. 2013;84: 588-602.

Cowling RM, Rundel PW, Lamont BB, Arroyo MK, Arianoutsou M. Plant diversity in Mediterranean climate regions. Trends Ecol Evol. 1996;11: 362-366.

Delmont TO, Prestat E, Keegan KP, Faubladier M, Robe P, Clark IM, Pelletier E, Hirsch PR, Meyer F, Gilbert JA, Le Paslier D, Simonet P, Vogel TM. Structure, fluctuation and magnitude of a natural grassland soil metagenome. ISME J. 2011;6: 1677-1687. 
429 Fernández-Calviño D, Martín A, Arias-Estévez M, Bååth E, Díaz-Raviña M. Microbial 430 community structure of vineyard soils with different $\mathrm{pH}$ and cooper content. Appl Soil Ecol. 2010;46: 276-282.

432 Fierer N, Leff JW, Adams BJ, Nielsen UN, Bathes ST, Lauber CL, Owens S, Gilbert GA, Wall 433 DH, Caporaso, JG. Cross-biome metagenomic analyses of soil microbial communities and their functional attributes. Proc Nat Acad Sci USA. 2012;109: 21390-21395.

435 Fleet GH. Yeast interactions and wine flavour. Int J Food Microbiol. 2003;86: 11-22.

436 Fujita K, Furuya S, Kohno M, Suzuki S, Takayanagi T. Analysis of microbial community in

437

438

439

440

441

442

443

444

445

446

447

448

449

450

451 Japanese vineyard soils by culture-independent molecular approach. Int J Wine Res. 2010;2: 75-104.

Garbeva P, van Veen JA, van Elsas JD. Microbial diversity in soil: selection microbial populations by plant and soil type and implications for disease suppressiveness. Ann Rev Phytopathol. 2004;42: 243-270.

García-Orenes F, Morugán-Coronado A, Zornoza R, Scow K. Changes in soil microbial community structure influences by agricultural management practices in a Mediterranean agro-ecosystem. PLoS One 2013;8: e80522.

Gardi C, Montanarella L, Arrouays D, Bispo A, Lemanceau P, Jovilet C, Mulder C, Ranjard L, Römbke J, Rutgers M, Menta C. Soil biodiversity monitoring in Europe: ongoing activities and challenges. Eur J Soil Sci. 2009;60: 807-819.

Gilbert, J.A., van der Lelie, D., Zarraonaindia, I. Microbial terroir for wine grapes. Proc Natl Acad Sci USA. 2014;111: 5-6.

Griffiths BS, Philippot L. Insights into the resistance and resilience of the soil microbial community. FEMS Micriobiol Rev. 2013:37; 112-139. 
452 Hannah L, Roehrdanz PR, Ikegami M, Shepard AV, Shaw MR, Tabor G, Zhi L, Marquet PA,

453 Hijmans RJ. Climate change, wine, and conservation. Proc Natl Acad Sci USA. 2013;110:

$454 \quad 6907-6912$.

455 Heilmann-Clausen J, Barron ES, Boddy L, Dahlber A, Griffith GW, Nordén J, Ovaskainen O, 456 Perini C, Senn-Irlet B, Halme P. A fungal perspective on conservation biology. Conserv $457 \quad$ Biol 2014;29: 61-68.

458 Jangid K, Williams MA, Franzluebbers AJ, Sanderlin JS, Reeves JH, Jenkins MB, Endale DM, 459 Coleman DC, Whitman WB. Relative impacts of land-use, management intensity and 460 fertilization upon soil microbial community structure in agricultural systems. Soil Biol $461 \quad$ Biochem. 2008;40: 2843.2853.

462 Janssen PH. Identifying the dominant soil bacterial taxa in libraries of 16S rRNA and 16S rRNA 463 genes. Appl Environ Microbiol. 2006;72: 1719-1728.

464 Jenkins SN, Waite IS, Blackburn A, Husbund R, Rushton SP, Manning DC, O’Donnell AG. 465 Actinobacterial community dynamics in long term managed grasslands. A Van Leeuw J

466 Microb. 2010;95: 319-334.

467 Kasel S, Bennett LT, Tibbits J. Land use influences soil fungal community composition across 468 central Victoria, south-eastern Australia. Soil Biol Biotechnol. 2008;40: 1724-1732.

469 Lauber CL, Strickland MS, Bradford MA, Fierer N. The influence of soil properties on the 470 structure of bacterial and fungal communities across land-use types. Soil Biol Biochem.

471 2008;40: 2407-2415.

472 Mendes LW, Kuramae EE, Navarrete AA, van Veen JA, Tsai SM. Taxonomical and functional 473 microbial community selection in soybean rhizosphere. ISME J 2014;8: 1577-1587. 
474 Meyer F, Paarman D, D’Souza M, Olson R, Galss EM, Kubal M, Paczian T, Rodriguez A,

475 Steens R, Wilke A, Wilkening J, Edwards RA. The metagenomics RAST server: a public

476 resource for the automatic phylogenetic and functional analysis of metagenomes. BCM

$477 \quad$ Bioinformatics. 2008;9: 386.

478 Mills DA, Phister T, Neeley E, Johannsen E. Wine fermantation. In: Cocolin L, Ercolini D,

479 editors. Molecular Techniques in the Microbial Ecology of Fermented Foods. Berlin:

480 Springer-Verlag;2008. pp: 162-192.

481 Mittermeier RA, Turner WR, Larsen FW, Brooks TM, Gascon C. Global biodiversity

482 conservation: the critical role of hotspots. In: Zachos FE, Hable JC, editors. Biodiversity

483 Hotspots. Berlin: Springer-Verlag; 2011: pp: 3-22.

484 Miura T, Niswati A, Swibawa IG, Haryani S, Gunito H, Arai M, Yamada K, Shimano S, Kaneko

485 N, Fujie K. Shifts in the composition and potential functions of soil microbial communities

486 responding to a no-tillage practice and bagasse mulching on a sugarcane plantation. Biol

$487 \quad$ Fertil Soils. 2016;52: 307-322.

488 Montecchia MS, Tosi M, Soria MA, Vogrig JA, Sydorenko O, Correa OS. Pyrosequencing

489 revelas changes in soil bacteria communities after conversion of Yungas forests to

$490 \quad$ agriculture. PLoS One. 2015;10: e0119426.

491 Myers N, Mittermeier RA, Mittermeier CG, da Fonseca GA, Kent J. Biodiversity hotspots for 492 conservation priorities. Nature. 2000;403: 853-858.

493 Nannipieri P, Ascher J, Ceccherini MT, Landi L, Pietramellara G, Renella G. Microbial diversity $494 \quad$ and soil functions. Eur J Soil Sci. 2003;54: 655-670. 
495 O’Brien HE, Parrent JL, Jackson JA, Moncalvo J-M, Vilgalys R. Fungal community analysis by 496 large-scale sequencing of environmental samples. Appl Environ Microbiol. 2005;71:

497 $5544-5550$.

498

499

500

501

502

503

504

505

506

507

508

509

510

511

512

513

514

515

Oliveros JC. Venny. An interactive tool for comparing lists with Venn's diagrams. 2015.

Available at http://bioinfogp.cnb.csic.es/tools/venny/index.html (Accessed 23 June 2016).

Pampulha ME, Oliveira A. Impact of an herbicide combination of bromoxynil and prosulfuron on soil microorganisms. Curr Microbiol. 2006;53: 238-243.

Parks DH, Beiko RG. Identifying biologically relevant differences between metagenomic communities. Bioinformatics. 2010;26: 715-721.

Paula FS, Rodrigues JLM, Zhou J, Wu L, Mueller RC, Mirza BS, Bohannan BJM, Nüsslein K, Deng Y, Tiedje JM, Pellizari VH. Land use change alters functional gene diversity, composition and abundance in Amazon forest soil microbial communities. Mol Ecol. 2014;23: 2988-2999.

Pearce DA, Newsham KK, Thorne MAS, Calvo-Bado L, Krsek M, Laskaris P, Hodson A, Wellington EM. Metagenomic analysis of a southern maritime Antarctic soil. Front Microbiol. 2012;3: doi: 10.3389/fmicb.2012.00403

Spain AM, Krumholz LR, Elshahed MS. Abundance, composition, diversity and novelty of soil Proteobacteria. ISME J. 2009;3: 992-1000.

14 Tiedje JM, Asuming-Brempong S, Nusslein K, Marsh TL, Flynn SJ. Opening the black box of 15 soil microbial diversity. Appl Soil Ecol. 1999;13: 109-122. 
516 Underwood EC, Viers JH, Klausmeyer KR, Cox RL, Shaw MR. Threats and biodiversity in the 517 Mediterranean biome. Divers Distrib. 2008;15: 188-197.

518 Uroz S, Ioannidis P, Lengelle J, Cébron A, Morin E, Buée M, Martin F. Functional assays and 519 metagenomic analysis reveals differences between the microbial communities inhabiting 520 the soil horizons of a Norway spruce plantation. PLoS One. 2013;8: e55929.

521 van Leeuwen C, Friant P, Chone C, Tregoat O, Koundouras S, Dubourdieu D. Influence of 522 climate, soil, and cultivar on terroir. Am J Enol Viticult. 2004;55: 207-217.

523 Viers JH, Willimas JN, Nicholas KA, Barbosa O, Kotzé I, Spence L, Webb LB, Merenlender A, 524 Reynols M. Vinecology: pairing wine with nature. Conserv Let. 2013;6: 287-299.

525 Vitoussek PM, Mooney HA, Lubchenco J, Melillo JM. Human domination of Earth’s 526 ecosystems. Science. 1997;227: 194-199.

527 White JR, Nagarajan N, Pop M. Statistical methods for detecting differentially abundant features 528 in clinic metagenomic samples. PLoS Comput Biol. 2009;5: e1000352.

529 Xu Z, Hansen MA, Hansen LH, Jacquiod S, Sorensen S. Bioinformatic approaches reveal 530 metagenomic characterization of soil microbial community. PLoS One. 2014;9: e93445.

531 Zarraonaindia I, Owens SM, Welsenhorn P, West K, Hampton-Marcell J, Lax S, Bokulich NA, 532 Mills DA, Martin G, Taghavi S, van der Lelie D, Gilbert JA. The soil microbiome 533 influences grapevine-associated microbiota. mBio. 2015;6: e02527. 
Table $\mathbf{1}$ (on next page)

Descriptive information of each sampling site. 


\begin{tabular}{|c|c|c|c|}
\hline & Ocoa, Chile & Leyda, Chile & Apalta, Chile \\
\hline Latitude & $32^{\circ} 52^{\prime} \mathrm{S}$ & $33^{\circ} 34^{\prime} \mathrm{S}$ & $34^{\circ} 36^{\prime} \mathrm{S}$ \\
\hline Longitude & $71^{\circ} 7^{\prime} \mathrm{W}$ & $71^{\circ} 22^{\prime} \mathrm{W}$ & $71^{\circ} 7^{\prime} \mathrm{W}$ \\
\hline Altitude & $307 \mathrm{~m}$ & $216 \mathrm{~m}$ & $268 \mathrm{~m}$ \\
\hline Mean temperature & $14.7^{\circ} \mathrm{C}$ & $16.2^{\circ} \mathrm{C}$ & $14.6^{\circ} \mathrm{C}$ \\
\hline Precipitation & $354 \mathrm{~mm}$ & $457 \mathrm{~mm}$ & $731 \mathrm{~mm}$ \\
\hline $\mathrm{pH}$ forest soil ${ }^{1}$ & 7.87 & 6.86 & 6.34 \\
\hline $\mathrm{pH}$ vineyards soil ${ }^{2}$ & $8.1 \pm 0.1$ & $7.8 \pm 0.5$ & $7.5 \pm 0.4$ \\
\hline $\begin{array}{l}\text { Forest soil content } \\
\text { (sand, silt and clay) }\end{array}$ & $73 \%-16 \%-11 \%$ & $67 \%-22 \%-11 \%$ & $47 \%-37 \%-15 \%$ \\
\hline $\begin{array}{l}\text { Vineyard soil content } \\
\text { (sand, silt and clay) }\end{array}$ & $56 \%-38 \%-16 \%$ & $61 \%-26 \%-13 \%$ & $61 \%-27 \%-12 \%$ \\
\hline Soil taxonomy & Alfisol & Alfisol & Alfisol \\
\hline Vine variety & Cabernet Sauvignon & Sauvignon Blanc & Syrah \\
\hline Planting year $( \pm$ SD $)$ & $2002 \pm 3$ & $2006 \pm 1$ & $2001 \pm 4$ \\
\hline
\end{tabular}

$2{ }^{1} \mathrm{pH}$ in forests was determined from a single soil sample, whereas ${ }^{2} \mathrm{pH}$ in vineyards was 3 determined in each plot and the mean ( \pm standard deviation) is shown. 


\section{Table 2 (on next page)}

Abundances of taxonomic groups in forest and vineyard soils.

Values are shown as percentage of abundance in each habitat (mean \pm standard deviation) $P$-values were derived from a Kruskal-Wallis test. 


\begin{tabular}{|c|c|c|c|c|c|c|}
\hline Taxa & \multicolumn{3}{|c|}{ Forest } & \multicolumn{2}{|c|}{ Vineyard } & $P$-value \\
\hline Archaea & 0.454 & \pm & $\mathbf{0 . 0 5 0}$ & 0.486 & $\pm \mathbf{0 . 0 7 7}$ & 0.83 \\
\hline Crenarchaeota & 0.050 & \pm & 0.007 & 0.048 & \pm 0.003 & 0.51 \\
\hline Euryarchaeota & 0.376 & \pm & 0.040 & 0.395 & \pm 0.054 & 0.83 \\
\hline Korarchaeota & 0.004 & \pm & 0.002 & 0.004 & \pm 0.002 & 0.83 \\
\hline Thaumarchaeota & 0.021 & \pm & 0.015 & 0.036 & \pm 0.019 & 0.28 \\
\hline Unclassified & 0.003 & \pm & 0.001 & 0.004 & \pm 0.001 & 0.66 \\
\hline Bacteria & 90.34 & \pm & 0.561 & 90.43 & $\pm \quad 0.073$ & 0.72 \\
\hline Acidobacteria & 5.118 & \pm & 0.748 & 5.080 & \pm 0.841 & 0.83 \\
\hline Actinobacteria & 20.49 & \pm & 2.532 & 20.17 & \pm 1.732 & 0.83 \\
\hline Aquificae & 0.098 & \pm & 0.005 & 0.105 & \pm 0.009 & 0.38 \\
\hline Bacteroidetes & 3.049 & \pm & 0.502 & 3.369 & \pm 0.576 & 0.51 \\
\hline Chlamydiae & 0.051 & \pm & 0.014 & 0.050 & \pm 0.013 & 0.83 \\
\hline Chlorobi & 0.315 & \pm & 0.030 & 0.321 & \pm 0.034 & 0.83 \\
\hline Chloroflexi & 1.918 & \pm & 0.304 & 2.017 & \pm 0.250 & 0.83 \\
\hline Chrysiogenetes & 0.015 & \pm & 0.005 & 0.016 & \pm 0.005 & 0.83 \\
\hline Cyanobacteria & 1.774 & \pm & 0.236 & 1.819 & \pm 0.190 & 0.51 \\
\hline Deferribacteres & 0.048 & \pm & 0.006 & 0.048 & \pm 0.005 & 0.83 \\
\hline Deinococcus-Thermus & 0.574 & \pm & 0.043 & 0.599 & \pm 0.049 & 0.51 \\
\hline Dictyoglomi & 0.035 & \pm & 0.010 & 0.046 & \pm 0.002 & 0.27 \\
\hline Elusimicrobia & 0.012 & \pm & 0.002 & 0.016 & \pm 0.004 & 0.27 \\
\hline Fibrobacteres & 0.006 & \pm & 0.001 & 0.010 & \pm 0.003 & 0.08 \\
\hline Firmicutes & 2.945 & \pm & 0.296 & 3.313 & \pm 0.295 & 0.13 \\
\hline Fusobacteria & 0.028 & \pm & 0.003 & 0.030 & \pm 0.011 & 0.51 \\
\hline Gemmatimonadetes & 1.465 & \pm & 0.208 & 1.542 & \pm 0.180 & 0.28 \\
\hline Lentisphaerae & 0.030 & \pm & 0.010 & 0.037 & \pm 0.003 & 0.28 \\
\hline Nitrospirae & 0.200 & \pm & 0.018 & 0.193 & \pm 0.037 & 0.51 \\
\hline Planctomycetes & 3.001 & \pm & 0.062 & 3.425 & \pm 0.617 & 0.13 \\
\hline Ptobacteria & 0.019 & \pm & 0.003 & 0.021 & \pm 0.007 & 0.83 \\
\hline Proteobacteria & 46.12 & \pm & 0.245 & 45.12 & \pm 1.481 & 0.28 \\
\hline Spirochaetes & 0.235 & \pm & 0.019 & 0.228 & \pm 0.015 & 0.83 \\
\hline Synergistetes & 0.054 & \pm & 0.003 & 0.062 & \pm 0.010 & 0.13 \\
\hline Tenericutes & 0.001 & \pm & 0.001 & 0.002 & \pm 0.001 & 0.27 \\
\hline Thermotogae & 0.104 & \pm & 0.010 & 0.134 & \pm 0.025 & 0.13 \\
\hline Verrucomicrobia & 2.224 & \pm & 0.656 & 2.210 & \pm 0.249 & 0.83 \\
\hline Unclassified & 0.419 & \pm & 0.040 & 0.439 & \pm 0.042 & 0.28 \\
\hline Eukaryota & 0.582 & \pm & 0.162 & 0.434 & $\pm \mathbf{0 . 1 3 9}$ & 0.51 \\
\hline
\end{tabular}




\begin{tabular}{llllll} 
Ascomycota & 0.462 & \pm 0.102 & 0.339 & \pm 0.131 & 0.28 \\
Basidiomycota & 0.032 & \pm 0.013 & 0.026 & \pm 0.003 & 0.83 \\
$\quad$ Unclassified & 0.088 & \pm 0.056 & 0.069 & \pm 0.014 & 0.51 \\
& & \pm & & \pm & \\
Viruses & $\mathbf{0 . 0 0 2}$ & $\pm \mathbf{0 . 0 0 8}$ & $\mathbf{0 . 0 0 1} \pm \mathbf{0 . 0 0 9}$ & $\mathbf{0 . 4 9}$ \\
Unassigned/Unclassified & $\mathbf{8 . 6 2 4}$ & $\pm \mathbf{0 . 3 7 0}$ & $\mathbf{8 . 6 2 3}$ & $\pm \mathbf{0 . 1 1 5}$ & $\mathbf{0 . 5 1}$ \\
& & & & & \\
\hline
\end{tabular}

1

2 


\section{Table 3(on next page)}

Diversity indices for microbial communities from forest and vineyard soils.
A) Diversity indices for microbial communities, and B)
B) Shannon richness related to functional categories likely associated with nutrient cycling. Values are shown as percentage of abundance for each habitat (mean \pm standard deviation) $P$-values were derived from a Kruskal-Wallis test. 
1

\begin{tabular}{|c|c|c|c|c|c|c|c|}
\hline \multirow{2}{*}{$\begin{array}{l}\text { A) Index } \\
\text { Richness }\end{array}$} & \multicolumn{3}{|c|}{ Forest } & \multicolumn{3}{|c|}{ Vineyard } & \multirow{2}{*}{$\begin{array}{c}P \text {-value } \\
0.05\end{array}$} \\
\hline & 5101 & \pm & 14.7 & 5251 & \pm & 28.6 & \\
\hline Shannon diversity & 7.175 & \pm & 0.054 & 7.209 & \pm & 0.075 & 0.51 \\
\hline Shannon richness & 517.0 & \pm & 15.4 & 530.6 & \pm & 32.5 & 0.83 \\
\hline Pielou evenness & 0.840 & \pm & 0.007 & 0.843 & \pm & 0.009 & 0.51 \\
\hline B) Shannon richness & \multicolumn{3}{|c|}{ Forest } & \multicolumn{3}{|c|}{ Vineyard } & P-value \\
\hline Nitrogen metabolism & 287.8 & \pm & 20.0 & 295.9 & \pm & 11.2 & 0.51 \\
\hline Phosphorous metabolism & 286.7 & \pm & 11.9 & 258.5 & \pm & 22.5 & 0.13 \\
\hline Potassium metabolism & 183.6 & \pm & 11.1 & 193.5 & \pm & 12.7 & 0.28 \\
\hline
\end{tabular}

2 
Figure 1

Numbers and percentage of bacterial species found in forest and vineyard soils.

The number in the overlapping zone indicates how many species were shared between forest and vineyard soils, and the numbers in the non-overlapping zone indicate how many species were exclusively found in each habitat.

Forest

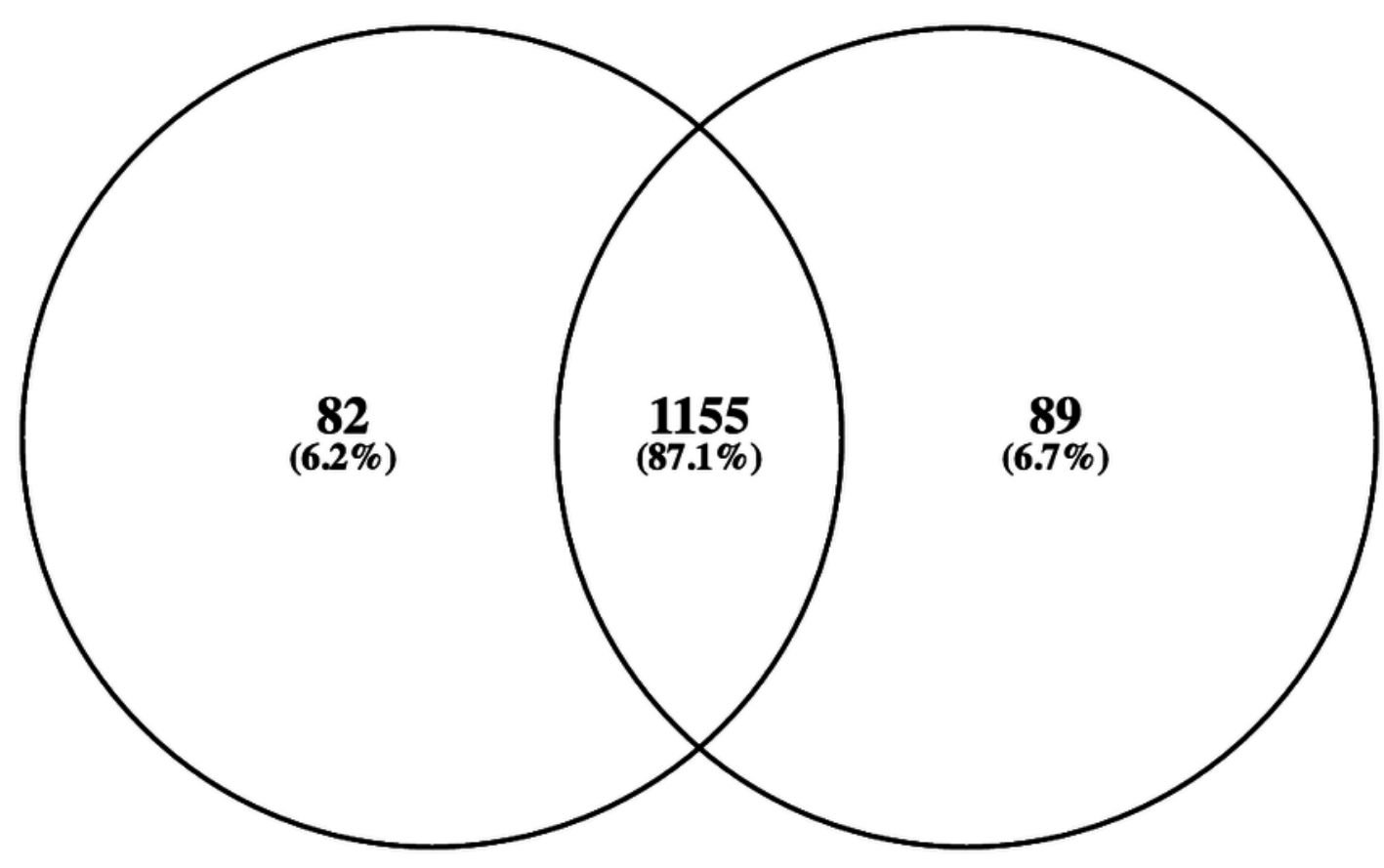


Figure 2 (on next page)

Ordination plot for microbial composition in soils.

Ordination plot from the canonical correspondence analysis (CCA) based on the abundance of OTUs found the microbial communities found in forest and vineyard soils. 


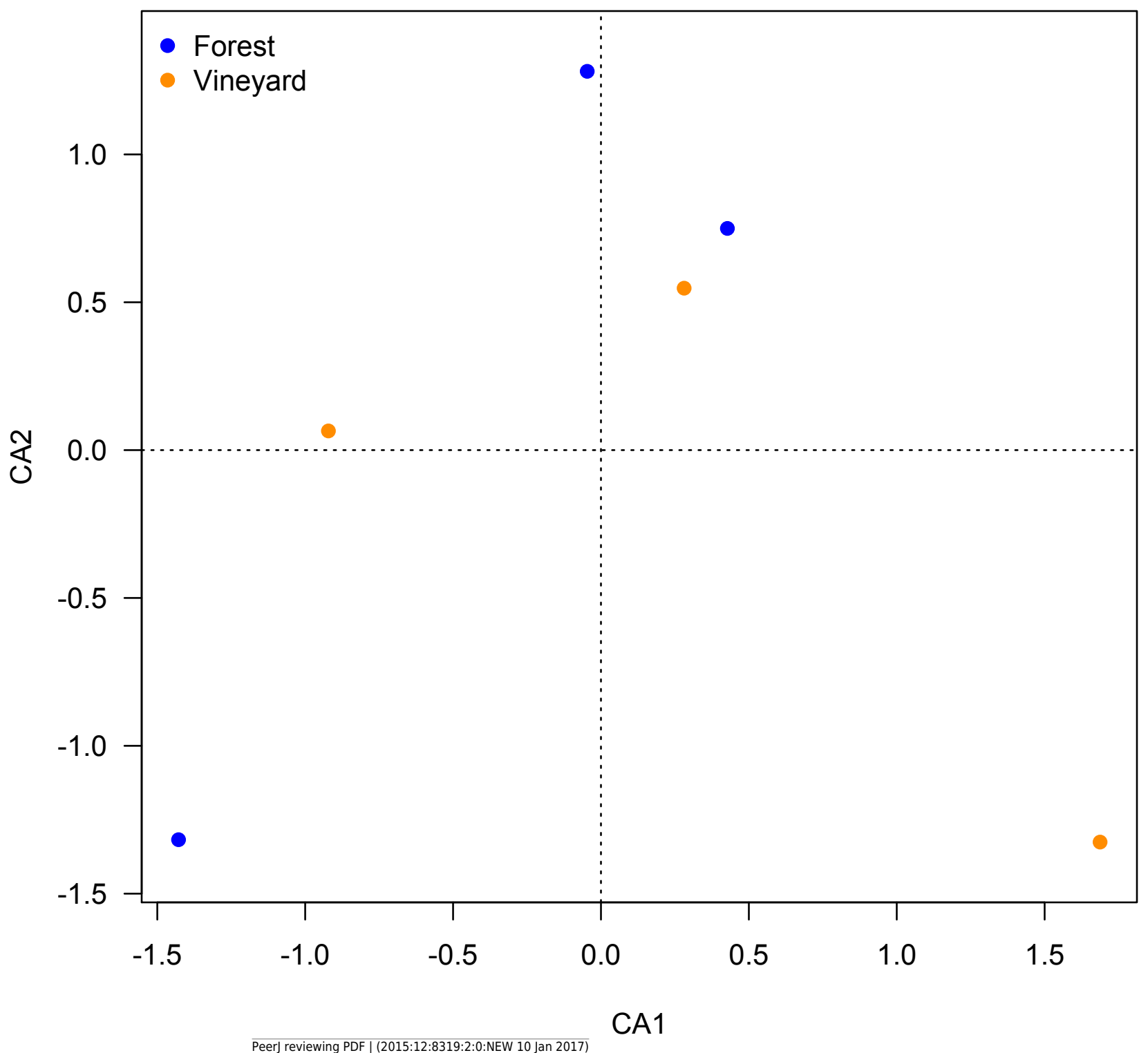


Figure 3 (on next page)

Ordination plot for metabolic categories in soils

Ordination plot from the canonical correspondence analysis (CCA) based on the relative abundances (points) and component loadings (text) of individual functional categories (SEED subsystem level 1) of the microbial communities found in forest and vineyard soils. 


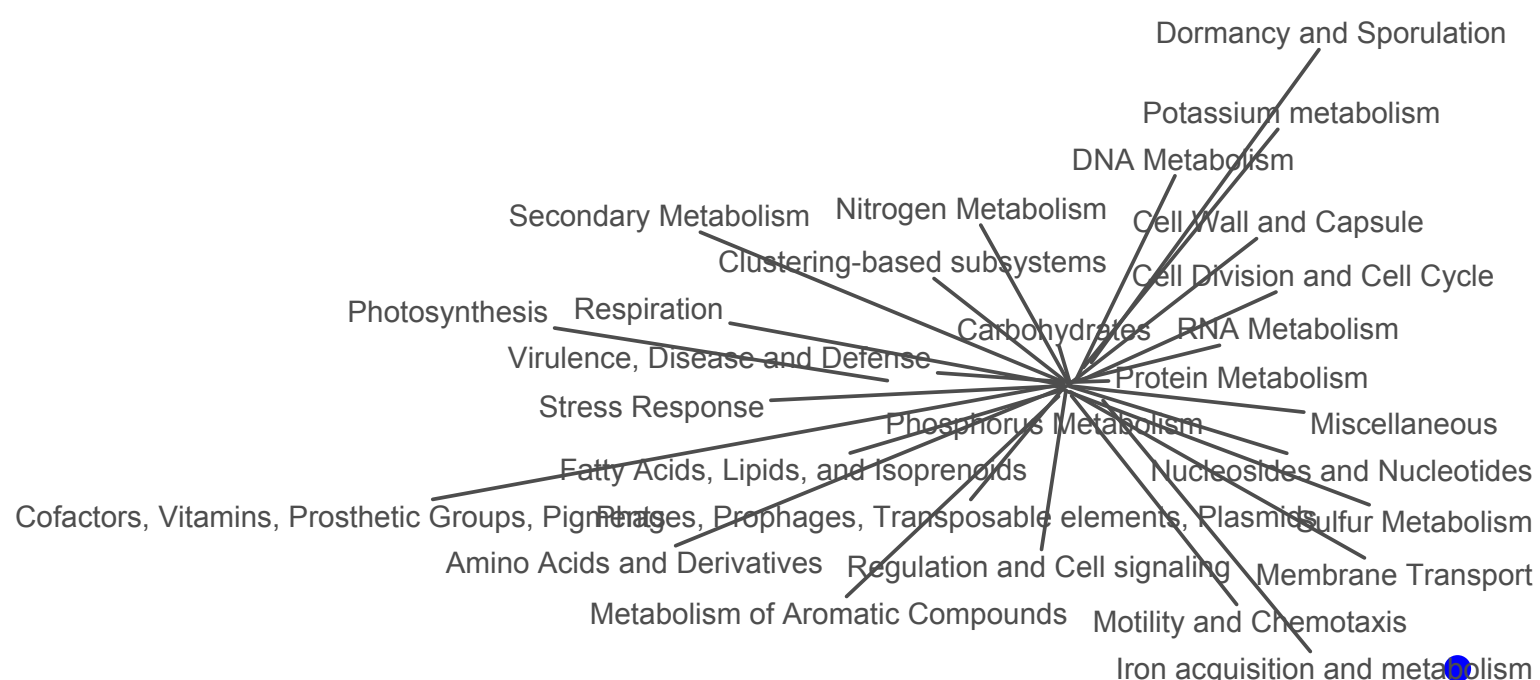

Habitat 
Figure 4 (on next page)

Functional categories found in soil microbial communities

Bar plot showing the mean proportion (\%) of functional categories found in soil microbial communities based on the Subsystem database. Points indicate the differences between forest and vineyard soils (blue and orange bars, respectively), and the values at the right show the $p$-values were derived from a White's non-parametric t-test (White et al. 2009). 
Amino Acids and Derivatives

Secondary Metabolism

Fatty Acids, Lipids, and Isoprenoids

Miscellaneous

Nucleosides and Nucleotides

Potassium metabolism

Protein Metabolism

Metabolism of Aromatic Compounds

Carbohydrates

DNA Metabolism

Regulation and Cell signaling

Motility and Chemotaxis

Clustering-based subsystems

Stress Response

Cell Division and Cell Cycle

Photosynthesis

Dormancy and Sporulation

Sulfur Metabolism

Virulence, Disease and Defense

Respiration

Iron acquisition and metabolism

Phages, Prophages, Transposable elements, Plasmids

RNA Metabolism

Nitrogen Metabolism

Phosphorus Metabolism

Cell Wall and Capsule

Cofactors, Vitamins, Prosthetic Groups, Pigments

Membrane Transport t95\% cenfidenge intervals

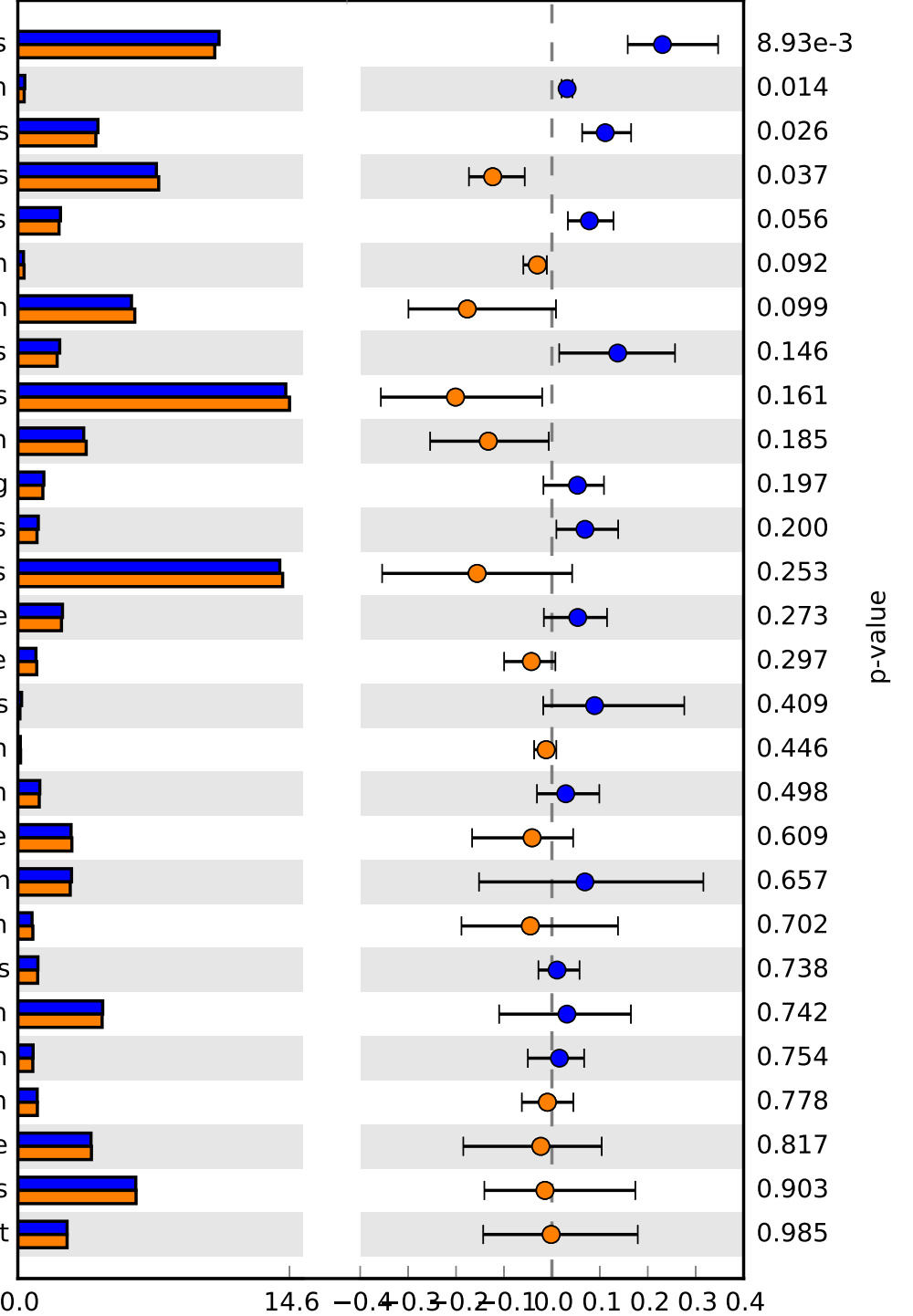

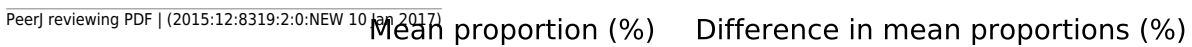

